\title{
Prevalence of Primary Open Angle Glaucoma in Patients with Hypertension
}

\author{
Archana Pushpakaran', Sedhu P. A², Ashwati Sankar ${ }^{3}$, Cyriac Kurien ${ }^{4}$ \\ ${ }^{1}$ Associate Professor, SreeNarayana Institute of Medical Sciences, Chalakka, Kochi, ${ }^{2}$ Professor, SreeNarayana Institute of Medical Sciences, Chalakka, Kochi, \\ ${ }^{3}$ Assistant Professor, SreeNarayana Institute of Medical Sciences, Chalakka, Kochi, ${ }^{4}$ Professor \& HOD, SreeNarayana Institute of Medical Sciences, Chalakka, \\ Kochi.
}

\section{Abstract}

Background: Glaucoma is the second most common cause of blindness worldwide. It is one of the leading causes of irreversible blindness in the adult population worldwide. Glaucoma is a progressive optic neuropathy. The present study was conducted to assess prevalence of primary open angle glaucoma in patients with hypertension. Subjects and Methods: This cross- sectional study was conducted in outpatient department of Sree Narayana Institute of Medical Sciences. A total of 100 patients with hypertension were included in the study. Prevalence of primary open angle glaucoma in patients with HTN was recorded. Results: Out of 100,59 were males and 41 were females. Among the 100 hypertensive patients, 5\% of patients had POAG. Among POAG, 3 were males and 2 were females. The percentage of patients with IOP between $8-21$ was $95 \%$, IOP $>21$ was $5 \%$ in right eye. The percentage of patients with IOP in between $8-21$ was $95 \%$, IOP $>21$ was $5 \%$ in left eye. Conclusion: High myopia, hypertension, diabetes mellitus has been associated with POAG, however, direct and convincing evidences are still lacking.

Keywords: Glaucoma, Primary open angle glaucoma, hypertension.

Corresponding Author: Dr. Sedhu P.A, Professor, SreeNarayana Institute of Medical Sciences, Chalakka, India.

Email: dr.sedhu@gmail.com

Received: January 2020

Accepted: January 2020

\section{Introduction}

Glaucoma is the second most common cause of blindness worldwide. It is a major global issue, causing significant ocular morbidity and disability due to its progressive nature resulting in an irreversible visual loss. Due to its chronicity, it is often also dubbed as a "silent killer" of the eye. Patients are usually asymptomatic until very advanced stage, making visual loss irrecoverable by the time they present to an ophthalmologist. ${ }^{[1]}$

One of its variant and the most common form - primary open-angle glaucoma (POAG) is a chronic, progressive, and anterior optic neuropathy that is associated with characteristic cupping and atrophy of the optic disc, visual field loss, open angles, and no obvious causative ocular or systemic conditions. POAG accounts for nearly three quarters $(74 \%)$ of all glaucoma cases. ${ }^{[2]}$

Hypertension (HT) and cardiovascular disorders are the most common systemic diseases seen in glaucoma subjects. Hypertension (HTN) data on the relationship among HTN and intraocular pressure (IOP) are consistent across examination. This relation between POAG and blood pressure (BP) is unpredictable and inadequately understood. ${ }^{[3]}$

Among vascular factors, it has been long postulated that systemic HTN may cause increases in IOP mainly via overproduction from ciliary body or impaired outflow of aqueous humor. However, this relationship remains inconclusive and under debate. While some studies highlight that systemic HTN is a risk factor for glaucoma, other studies indicate that low systemic BP is more dangerous and poses a serious risk for the development and progression of glaucoma. ${ }^{[4]}$ The present study was conducted to assess prevalence of primary open angle glaucoma in patients with hypertension.

\section{Subjects and Methods}

The present cross- sectional study was conducted in outpatient department of Sree Narayana Institute of Medical Sciences. It comprised of 100 patients with hypertension. The study was approved by the institutional ethics committee.

Data such as name, age, gender etc. was recorded. In all thorough physical examination was performed. Best corrected visual acuity (BCVA) was assessed using an illuminattxSnellen's chart. Near vision was assessed, using Jaeger's near vision chart. Colour vision was checked using Ishihara's pseudo-isochromatic charts. BCVA was checked by Skiascopy or streak retinoscopy. Slit lamp examination was performed to rule out anterior segment pathology. Gonioscopy was done with Goldmann's three mirror goniolens and the anterior chamber angle was graded according to modified Shaffer's grading. 
Dilated fundus examination by indirect ophthalmoscopy, followed by a slit lamp biomicroscopic evaluation with 78 $\mathrm{D}$ lens and $90 \mathrm{D}$ lens to evaluate the posterior pole including the optic disc was done. Patients were evaluated for some parameters such as C:D ratio, 10P, visual fields, each eye separately. Data was presented as mean and standard deviation for continuous variables. Statistical significance was considered when $\mathrm{P}$ was $<0.05$.

\section{Results}

\begin{tabular}{l} 
Table 1: Distribution of patients \\
\begin{tabular}{|l|l|l|}
\hline Total- 100 & Males & Females \\
\hline Gender & 59 & 41 \\
\hline Number &
\end{tabular} \\
\hline
\end{tabular}

[Table 1] shows that out of 100, 59 were males and 41 were females.

\section{Table 2: Prevalence of POAG}

\begin{tabular}{|l|l|l|}
\hline Classification & Count & \% \\
\hline Normal & 95 & 95.0 \\
\hline ACG & 0 & 0.0 \\
\hline POAG & 5 & 5.0 \\
\hline Total & 100 & 100.0 \\
\hline
\end{tabular}

[Table 2] shows that among the 100 hypertensive patients, $5 \%$ of patients had POAG.

\begin{tabular}{|l|l|l|}
\hline Table 3: Sex distribution in patients with POAG \\
\hline Gender & Count & \% \\
\hline Male & 3 & 60.0 \\
\hline Female & 2 & 40.0 \\
\hline Total & 5 & 100.0 \\
\hline
\end{tabular}

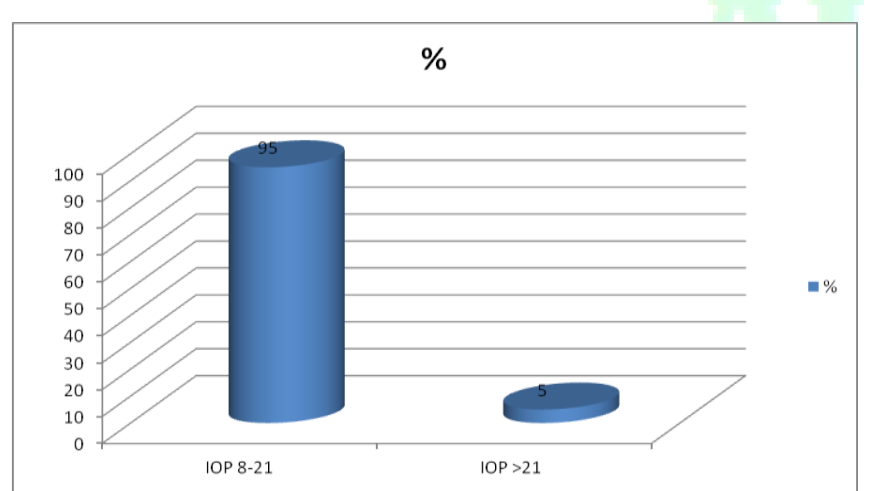

Figure 1: IOP variation in RE

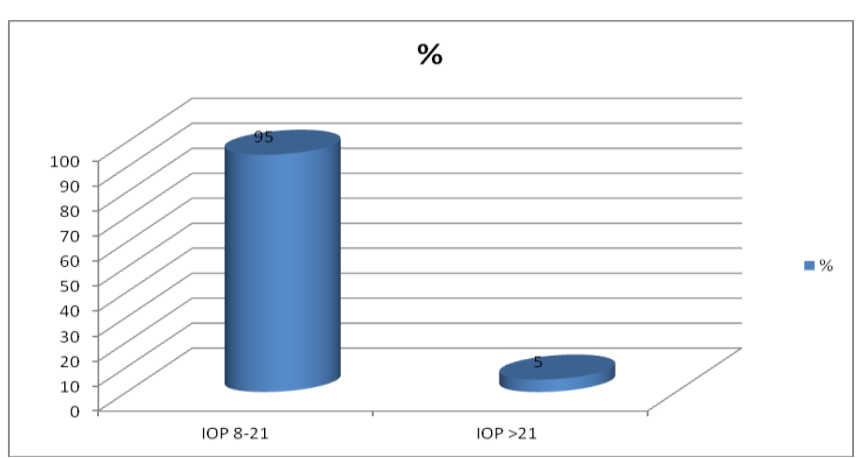

Figure 2: IOP variation in LE
Table 3 shows that 3 were males and 2 were females. Figure 1 shows that the percentage of patients with IOP in RE between $8-21$ was $95 \%$, IOP > 21 was $5 \%$.

Figure 2 shows that the percentage of patients with IOP in LE between $8-21$ was $95 \%$, IOP > 21 was $5 \%$.

\section{Discussion}

In addition to the effect of these systemic illnesses on glaucoma, the interplay of multiple medications used to manage these co-existing ocular and systemic diseases needs to be taken into consideration both by the treating physician and ophthalmologist. ${ }^{[5]}$ While in some cases systemic medications may decrease the intraocular pressure (IOP)-lowering effect of the topical medications, the simultaneous use of some ocular and systemic medications may lead to more sinister effects like metabolic disorders and cardio respiratory depression. ${ }^{[6]}$ The present study was conducted to assess prevalence of primary open angle glaucoma in patients with hypertension.

In this study, out of 100,59 were males and 41 were females. Among the 100 hypertensive patients, 5\% of patients had POAG. Bonomi et al, ${ }^{[7]}$ conducted a study to record the prevalence and systemic control and evaluate the adequacy of therapy of hypertension (HT) in glaucoma patients. Consecutive cases with primary open-angle glaucoma (POAG) or primary angle closure glaucoma (PACG) attending the outpatient services were evaluated for the presence of HT and any systemic/ocular medications being taken were recorded. Of 615 glaucoma cases evaluated, $281(45.7 \%)$ were POAG and $334(54.3 \%)$ were PACG. Two hundred and ninety-two $(47.5 \%)$ glaucoma patients had HT and 181 (29.4\%) had DM, including 97 $(15.8 \%)$ patients who had both. One hundred and thirtythree $(47.3 \%)$ patients with POAG and 159 (47.6\%) patients with PACG had HT. Ninety-seven (34.5\%) POAG patients and $84(25.1 \%)$ PACG patients were diabetics.

In this study, males were 3 and females were 2 . The percentage of patients with IOP between 8-21 was 95\%, I0P $>21$ was $5 \%$. The percentage of patients with IOP in LE between $8-21$ was $95 \%$, IOP > 21 was $5 \%$.

Dielemans et $\mathrm{al}^{\left[{ }^{[8]}\right.}$ evaluated associated risk factors in POAG. A total of 221 patients were enrolled in the study. The mean age of the patients was $54.4(\mathrm{SD} \pm 15.9)$ years with a male to female ratio of $0.93: 1$. Of the 221 patients, $68(31 \%)$ had a family history of POAG. Mean intraocular pressure was $15.8 \pm 4.87 \mathrm{mmHg}$, and mean central corneal thickness was $535.4 \pm 34.9 \mu \mathrm{m}$. A total of $81(36 \%)$ patients had HTN. The severity of POAG was found to be significantly higher in patients with HTN, DM, or both when evaluated on the basis of anatomical and functional. BP has a direct influence on IOP and ocular perfusion pressure. In addition, chronic HT due to generalized vascular damage causes impaired ocular blood flow and disturbs autoregulation. This over a long period of time can cause ganglion cell loss and potentiate the glaucomatous optic neuropathy. The importance of adequate control of this potential risk factor in the management of glaucoma 
cannot be overemphasized. ${ }^{[9]}$

\section{Conclusion}

Glaucoma, one of the leading causes of irreversible blindness in the adult population worldwide, is a progressive optic neuropathy. Primary open angle glaucoma (POAG) is the most commonly reported type of glaucoma in population based prevalence studies worldwide. Many studies found that high myopia, hypertension, diabetes mellitus has been associated with POAG, however, direct and convincing evidences are still lacking.

\section{References}

1. Quigley HA, Broman AT. The number of people with glaucoma worldwide in 2010 and 2020. Br J Ophthalmol 2006; 90:262-267.

2. Salim S, Shields MB. Glaucoma and systemic diseases. SurvOphthalmol 2010; 55:64-77.

3. Wise LA, Rosenberg L, Radin RG, Mattox C, Yang EB, Palmer JR, Seddon JM. A prospective study of diabetes, lifestyle factors, and glaucoma among African- American women. Ann Epidemiol 2011; 21:430-439.

4. Pasquale LR, Kang JH, Manson JE, Willett WC, Rosner BA, Hankinson SE. Prospective study of type 2 diabetes mellitus and risk of primary open-angle glaucoma in women. Ophthalmology 2006; 113:1081-1086.

5. Mitchell P, Lee AJ, Rochtchina E, Wang JJ. Open angle glaucoma and systemic hypertension: the Blue Mountains Eye Study. J Glaucoma 2004; 13:319-326.

6. Chopra V, Varma R, Francis BA, Wu J, Torres M, Azen SP, Los Angeles Latino Eye Study Group Type 2 diabetes mellitus and the risk of open-angle glaucoma the Los Angeles Latino Eye Study. Ophthalmology 2008; 115:227-232

7. Bonomi L, Marchini G, Marraffa M, Bernardi P, Morbio R, Varotto A. Vascular risk factors for primary open angle glaucoma: the EgnaNeumarkt Study. Ophthalmology. 2000;107(7):1287-1293.

8. Dielemans I, Vingerling JR, Wolfs RC, Hofman A, Grobbee DE, de Jong PT. The prevalence of primary openangle glaucoma in a populationbased study in the Netherlands. The Rotterdam Study. Ophthalmology 1994;101(11):1851-1855.

9. Lin $\mathrm{HC}$, Chien $\mathrm{CW}, \mathrm{Hu} \mathrm{CC}$, Ho JD. Comparison of comorbid conditions between open-angle glaucoma patients and a control cohort: a case-control study. Ophthalmology 117:2088-2095.

Copyright: (C) the author(s), 2020. It is an open-access article distributed under the terms of the Creative Commons Attribution License (CC BY 4.0), which permits authors to retain ownership of the copyright for their content, and allow anyone to download, reuse, reprint, modify, distribute and/or copy the content as long as the original authors and source are cited.

How to cite this article: Pushpakaran A, Sedhu PA, Sankar A, Kurien C. Prevalence of Primary Open Angle Glaucoma in Patients with Hypertension. Asian J. Med. Res. 2020;9(1):OT09-OT11.

DOI: dx.doi.org/10.47009/ajmr.2020.9.1.OT3

Source of Support: Nil, Conflict of Interest: None declared. 